\title{
A cidade na superfície e nas margens do dizer: discursos, memórias e identidades em sites de turismo
}

\section{The city on the surface and banks of saying: discourses, memories and identities in tourism sites}

\author{
Ilza Galvão CUTRIM \\ Universidade Federal do Maranhão (UFMA) \\ Mônica da Silva CRUZ \\ Universidade Federal do Maranhão (UFMA)
}

\begin{abstract}
RESUMO: Este artigo apresenta resultados de uma pesquisa sobre a construção discursiva da cidade de São Luís, em sites de Turismo, desenvolvida no interior do Grupo de Pesquisa e Estudos em Linguagem e Discurso do Maranhão (GPELD), da Universidade Federal do Maranhão. O estudo avalia imagens da cidade construídas na divulgação de festas populares maranhenses, especificamente a festa do Bumba-meu-boi. Analisam-se dois sites voltados para a propagação do Turismo. A pesquisa pauta-se em princípios da Análise do Discurso de vertente francesa, de base foucaultiana. Os resultados apontam que uma rede de sentidos edifica a capital maranhense a partir do ideal de espaço democrático, tendo por base o discurso da diversidade cultural.
\end{abstract}

PALAVRAS-CHAVE: Discurso, cidade, memória, identidades

\begin{abstract}
This paper presents results of a research on the discursive construction of São Luís city, in tourism sites. The research was developed by the Group for Research and Studies in Language and Discourse of Maranhão (GPELD), Federal University of Maranhão. The study evaluates images of the city built in the dissemination of popular festivals, specifically the Bumba-meu-boi. We analyzed two websites focused on the spread of Tourism. The research is based on principles of French Discourse Analysis, from Foucault base. The results show that a network senses builds the city of São Luís from the ideal of democratic space, based on the discourse of cultural diversity.
\end{abstract}

KEYWORDS: Discourse, city, memory, identity

\section{Introdução}

Segundo Hall (2008, p.49), as diferenças regionais e étnicas são colocadas gradualmente, sob uma espécie de "teto político do estado-nação", tornado fonte rica de significados para as identidades nacionais modernas. Nesse processo, a instantaneidade das comunicações tem exercido, indiscutivelmente, papel importante, propiciando uma espécie de "homogeneização do espaço global", contribuindo para que todos os lugares hoje sejam bem parecidos e que "o lugar esteja hoje em todo lugar" (ABREU, 2014, p.20).

A mídia, principalmente em sua versão eletrônica, tem se constituído em um dos maiores e mais fortes lugares de difusão de identidades, agindo sobre a produção 
identitária não só de pessoas, mas de lugares e situações (GREGOLIN, 2008). No espaço midiático, são infinitos os recursos que criam efeitos de verdade, valendo citar a exposição de imagens, o jogo de memória ou mesmo os discursos que neles circulam. Os meios midiáticos, mais do que sistemas de transmissão de informações, são lugares de construção de significações, e a internet é uma grande peça dessa engrenagem. Compreender como os sentidos aí se erigem é entender também as distintas posições que os sujeitos são levados a ocupar, em nossa sociedade. Nesse movimento, observamse constantemente culturas nacionais sendo apresentadas de forma múltipla nas telas dos computadores, demarcando diferenças, instaurando memórias e sentidos de pertencimento aos povos. Assim, lugares e culturas antes nunca imaginados, ao serem divulgados mundialmente em algumas mídias, de forma quase instantânea passam a ser parada obrigatória para vários viajantes. Esse fluxo tem, contudo, muitas implicações, entre elas as econômicas, pois a visitação de pessoas a um lugar sempre o modifica financeiramente. Dessa maneira surgem os comércios turísticos.

De acordo com Abreu (2014), desde o século XIX, descobriu-se que a imagem urbana pode ser comercializada, gerando muitos lucros. Assim, algumas identidades da cidade de São Luís, bem como as de inúmeros outros lugares, tornaram-se alvo de campanhas turísticas, que têm na mídia eletrônica, atualmente, uma grande aliada. Com o fortalecimento da indústria do Turismo, a partir do século XX, além da emergência de fatores como a patrimonialização da cultura, mudanças no conceito de história e a própria afirmação da globalização, São Luís tornou-se destaque em meios de comunicação do país e do mundo, apontada como lugar de cultura excêntrica, natureza exuberante e local de diversidade cultural (CARVALHO, 2009). Reportagens veiculadas em blogs e sites especializados que fazem referência à cidade dão-lhe as mais distintas identificações, traduzindo-a como espaço encantador, agregando-lhe valores a partir das singularidades de seus aspectos diferenciados, das suas práticas e saberes populares.

Entre os traços que têm definido a singularidade de São Luís em relação a outros

lugares destacam-se as festas populares, sempre cultivadas como elementos constitutivos do cotidiano pelos moradores da cidade, e em torno das quais uma tradição se edificou historicamente. Com as exigências da sociedade globalizada, houve a necessidade de significarem essas práticas festivas como marcas locais, em uma tentativa de territorializá-las, tornando-as, então, um dos principais cartões de visita da capital maranhense. Neste estudo, observa-se que ao apresentar a festa do Bumba-meuboi ao leitor, os meios de comunicação constroem imagens para a cidade de São Luís, resgatando memórias, instaurando outras, em um movimento que se estabelece na articulação entre discurso e poder. Dessa maneira, este artigo analisa imagens construídas para a cidade na divulgação da festa do Bumba-meu-boi em sites voltados para temas turísticos.

\section{Discursos e memórias: identi(ci)dades}

Mesmo que em alguns lugares o enfoque discursivo sobre os estudos urbanos dado à cidade ainda seja muito incipiente (SOUZA, 2014), sabe-se que já há algum 
tempo, no campo das linguagens, vem se discutindo o espaço citadino em sua dimensão simbólica, a partir da produção de sentidos. Nessa dimensão, ela deixa de ser apenas um complexo demográfico constituído por uma concentração populacional relevante, dada a atividades de caráter mercantil, industrial e cultural (FERREIRA, 1986) e passa a ser entendida como espaço simbólico, parte constitutiva da identidade de um povo. É, por essa razão, também um espaço simbólico e discursivo.

No plano discursivo, a cidade é um lugar de produção e circulação de sentidos e, assim sendo, gera várias significações, tornando-se articuladora de memórias, sujeita a transformações, pois é plena de linguagens, dotada de história, construtora de identidades e de inúmeros significados. Na visão de Orlandi (2001, p.32), a cidade deve ser percebida por seus atravessamentos, pelas memórias que a compõem. É um lugar onde o sujeito se inscreve historicamente, tomando sentidos para si e para os outros. A cidade, assim, é um espaço que significa e é significado, constituída por discursos de toda ordem.

A cidade de São Luís do Maranhão, como muitas cidades brasileiras, é construída por lugares históricos e modernos; por paisagens naturais e alguns monumentos; apresenta uma variedade de costumes resultantes da mistura cultural dos povos que a constituíram. Assim, a capital foi formando sua identidade a partir de uma rede de sentidos que surge de diferentes costumes, lugares, acontecimentos e pessoas. Essa cidade possui várias identidades, que se materializaram ao longo dos tempos, de distintas maneiras. No decorrer de sua história foi notada como Atenas Maranhense, Capital do Reggae, Jamaica Brasileira, Ilha do Amor, Manchester do Norte, Capital Brasileira da Cultura, Cidade Patrimônio Cultural da Humanidade etc. A fundação da cidade, entretanto, é controversa. Há pelo menos três versões para o acontecimento, sendo a mais divulgada a de que o gesto fundador teria vindo em 1642, por franceses.

Este artigo parte da perspectiva discursiva da observação da cidade, ao mobilizar a Análise do Discurso como um campo transdisciplinar, que se constitui no interior de saberes como a Linguística, a Psicanálise e o Marxismo e concebe o discurso como efeitos de sentidos, por entender que na linguagem não existe uma transparência. Esses efeitos derivam de uma relação não unilateral entre enunciador e enunciatário, os quais, sempre atravessados pelo simbólico, são sujeitos sociais. Em certas condições históricas, os sujeitos são afetados por sua memória discursiva, isto é, por informações já ditas, produzindo sentidos a partir de algo que fala antes. Os sentidos, dessa forma, constroem-se no discurso linguística e historicamente, isto é, os sentidos não brotam unicamente de uma estrutura, mas, sobretudo, de acontecimentos (PÊCHEUX, 2002).

Michel Foucault apresenta, em sua extensa obra, profundas e valiosas reflexões sobre a noção de discurso e suas possibilidades de circulação. Segundo esse autor, o discurso, enquanto dispositivo de enunciação, é o principal veículo de produção das identidades. Os discursos são práticas geradoras de significados, que se apoiam em regras históricas para estabelecerem o que pode ser dito, num certo campo discursivo e num dado contexto histórico (FOUCAULT, 1988).

Por essa via, entende-se o conceito de cultura como um dispositivo enunciativo, uma construção discursiva, a qual, conforme Santos (1994, p.45): 
[...] é uma construção histórica, seja como concepção, seja como dimensão do processo social. Ou seja, a cultura não é algo natural, não é uma decorrência de leis físicas ou biológicas. Ao contrário, a cultura é um produto coletivo da vida humana. Isso se aplica não apenas à percepção da cultura, mas também à sua relevância, à importância que passa a ter.

Portanto, o que se está considerando neste texto como cultura de um povo é um recorte de suas experiências, uma construção histórica, geralmente, uma elaboração sempre permeada por relações de poderes.

O Bumba-meu-boi, manifestação tradicional da cultura maranhense, tem passado por um profundo processo de reconfiguração de sentidos, no Estado (CRUZ, 2005), fato que se deve em grande parte à sua inserção em uma lógica social capitalista, em que o local é sempre peça importante para a constituição do global.

Em linhas gerais, a festa é a síntese de uma lenda sobre um casal de escravos, que trabalha para um fazendeiro - Chico (ou Pai Francisco, como preferem alguns) e Catirina. Certo dia, Catirina, grávida, deseja a língua do boi mais valioso da fazenda de seu senhor. Com medo de Catirina perder o filho, caso o desejo não seja atendido, Chico rouba o boi de seu patrão para atender a vontade de sua esposa. Ao descobrir o feito, o dono da fazenda sai em busca do escravo, contando com a ajuda dos vaqueiros e dos índios, que para ele trabalhavam. Os vaqueiros nada encontram. Então, o fazendeiro pede para os índios que o ajudem na procura. Os índios encontram Pai Chico e o boi, que havia morrido. Os índios levam Chico e o boi ao fazendeiro, que interroga o homem e descobre porque ele o havia levado. Os pajés são chamados e, após várias tentativas, conseguem ressuscitá-lo. O fazendeiro perdoa Pai Francisco e tudo se transforma em uma grande festa.

Em torno desse enredo, grupos de Bumba-meu-boi locais sustentam a tradição da festa, mantendo-a como prova da fé que têm em alguns santos católicos, pois muitos grupos, no Maranhão, nascem como pagamento de promessa por bênçãos alcançadas com a intercessão de São João. A temporada de apresentações dessa manifestação é o mês de junho, momento em que a cidade de São Luís é totalmente preparada para celebrar os festejos juninos. Ao entrar em uma rede de significações, engendrada por modelos econômicos atuais e pela própria história, o Bumba-meu-boi adquire gradualmente caráter universal, pois, conforme Hall (2008), na pós-modernidade, nada é tão local ou mundial.

Em uma incessante bricolagem de identidades nas mídias, diferentes discursos interagem para constituírem identificações à festa, e com esses discursos, uma imagem para a cidade de São Luís é também construída.

Importante destacar que identidade, aqui neste texto, está sendo considerada uma construção histórica e discursiva (HALL, 2008), um efeito de linguagem, conforme Gregolin (2008), distante, portanto, da concepção essencialista de sujeito.

$\mathrm{Na}$ construção das identidades, discurso e história se imbricam e também instauram memória, compreendida por Halbwachs (2006) como construção psíquica, que propicia uma representação seletiva do passado, nunca somente aquela do 
indivíduo, mas um conjunto de imagens que se constituem a partir de grupos sociais. Segundo o autor, apesar de os indivíduos terem lembranças de acontecimentos, somente os grupos sociais decidem o que é "memorável" e de que forma um fato será lembrado. Por esse viés, a memória é uma re-composição do passado. O indivíduo se constitui a partir de dois tipos de memória, uma individual e outra coletiva, e isso se dá por meio dos "instrumentos que são as palavras e as ideias, que o indivíduo não inventou, mas que toma emprestado de seu ambiente" (HALBWACHS, 2006, p. 72).

Para análise dessa construção, mobilizamos alguns princípios foucaultianos sobre discurso e história. De Foucault, tomamos o interesse em buscar as relações entre discurso, saber e história, diferentemente do historiador positivista, que se propõe descrever a continuidade do desenvolvimento de um pensamento, numa linha teleológica. A história, na visão foucaultiana, é constituída por múltiplos centros de poder, por uma dispersão de acontecimentos. Incrementando essa visão de história, Foucault chamou genealogia a uma forma de história que relata a constituição dos conhecimentos, dos discursos, do campo de influência dos objetos etc., "sem ter que se referir a um sujeito, tanto a um sujeito transcendental em relação ao campo dos acontecimentos, quanto um sujeito que persegue sua identidade vazia ao longo da história" (GIDDENS, 1998, p.316).

A relação saber/discurso/história é analisada com base no que o filósofo denomina prática discursiva. Como prática discursiva, o discurso para Foucault, é elemento fundamental da produção de verdades e, portanto, de poder e saber. O poder, em sua perspectiva, não está centralizado apenas em pontos específicos, como na escola, na família ou no Estado, mas se dissemina e se localiza no cotidiano, em práticas discursivas, tais como a medicina, a psiquiatria, a economia, o Direito ou a mídia. Esses espaços discursivos exercem seus poderes na organização da vida em sociedade. São essas práticas que formam a verdade de uma época. Essas premissas auxiliarão a análise proposta neste artigo, que toma a mídia como lugar de produção de identidades e de construção de memória.

A mídia aqui avaliada refere-se a sites voltados para o campo do turismo e do lazer escolhidos como locus de investigação por configurarem um regime de discursividade complexo, que se tornou um imperativo em nossa sociedade.

Os sítios constituem um programa de leitura que instaura leitores de identidades diversificadas e, por isso, precisam apresentar um conteúdo capaz de agradar muitas tribos. A internet, como um dos principais meios de divulgação de informações, da atualidade, pode então ser pensada como parte de um processo de entrelaçamento e produção de identidades, uma vez que a rede mundial de computadores está presente em muitas partes do planeta e é acessível a uma grande parcela da população.

\section{Sobre festa e cidade nos sites}

$\mathrm{Na}$ concepção foucaultiana, os discursos não podem ser entendidos como algo que possui um sentido oculto a ser exposto. O trabalho do analista é perscrutar os entornos do que é dito, para fazer emergir, na superfície desse dizer, as relações que o próprio discurso põe em funcionamento. Nesse sentido, buscam-se, nos sites 
selecionados, na face das coisas efetivamente ditas, os discursos que constroem identidades para a cidade a partir dos dizeres sobre a festa do Bumba-meu-boi; a que outros dizeres eles se filiam; que jogos de poderes são instituídos nesses sites; como esses espaços produzem um saber sobre a cidade e que sujeitos são autorizados a se identificar com ela nos sites.

Para iniciar as análises, apresenta-se o texto coletado em um site sobre Cidades Históricas ${ }_{2}^{1}$ declara-se que o Bumba-meu-boi:

arrasta maranhenses e visitantes por todos os cantos de São Luís, nos meses de junho e julho. Longe de ser uma festa criada para turistas, os bois se espalham nas periferias e no centro. Na parte nova ou antiga da cidade grupos de todo o Estado se reúnem em diversos arraiais para brincar até a madrugada (grifos nossos).

Esse fragmento sugere ao leitor que a manifestação não é um produto turístico, mas uma prática do cotidiano local. Como todo enunciado está sempre ligado a outros dizeres, negando-os ou reforçando-os, identifica-se na afirmação "Longe de ser uma festa criada para turistas (...)" o funcionamento de dizeres, que, por meio de uma memória discursiva, asseguram a estreita articulação entre festa, cidade e mercado turístico, no Maranhão. A memória discursiva corresponde ao que já foi dito antes, ao já-lá e funciona como aquilo que nutre o dizer e a interpretação. Desse modo, o enunciador situa a festa em uma rede de discursividades que a toma como mercadoria, produto feito para consumo e não apenas para o lazer. $O$ enunciador também, nesse parágrafo, edifica a festa como um espaço democrático, um lugar em que sujeitos do "centro" e da "periferia" da cidade com ela se identificam, fazendo emergir desse enunciado uma imagem não só para o Bumba-meu-boi, mas para a própria cidade de São Luís, como lugar que abriga uma cultura em que as diferenças podem conviver no mesmo espaço.

O discurso da diversidade emerge com acontecimentos como a problematização da história tradicional, com a emergência da noção de cultura proposto por Strauss (1978) e os questionamentos sobre as identidades, na modernidade líquida (BAUMAN, 2005).

No texto "Identidade: objeto ainda não identificado?", Gregolin (2008), discutindo o tratamento da identidade enquanto objeto da Análise do Discurso, analisa, do ponto de vista discursivo, o sujeito da pós-modernidade, que surge no momento a partir do qual "a identidade é dada por uma narrativa do eu, uma ilusão" (GREGOLIN, 2008, p.83). A fragmentação do sujeito e a ligação direta que mantém com os sistemas culturais relacionam-se sobre a fragmentação constitutiva do sujeito, na atualidade. Por ser um mosaico, uma construção inacabada, incompleto, o sujeito contemporâneo não pode adotar a identidade deste ou daquele sistema cultural, afirma a autora. Ao asseverar que o sujeito da pós-modernidade é dado por uma narrativa, observa-se o princípio da constituição das identidades por intermédio do discurso.

\footnotetext{
${ }^{1}$ Disponível em: http://www.cidadeshistoricas.art.br/saoluis/s__boi_p.php. Acesso em 10 de outubro de $\underline{2013}$
} 
No terceiro parágrafo, o enunciador deixa entrever a trajetória difícil da festa, por muito tempo vítima de preconceitos por parte das elites (intelectuais ou econômicas) da cidade. Esse estigma começou a se enfraquecer apenas com as transformações de conceitos como os de História, memória e cultura, mudanças que também se devem à relação desses conceitos com os efeitos da globalização, das redes econômicas mundiais. O site, assim, segue explicando de que modo a festa se revela atualmente e como era significada pela elite, no passado $^{2}$ :

Pajés e curandeiros são convocados para salvar o escravo e, quando o boi ressuscita urrando, todos participam de uma enorme festa para comemorar o milagre. Brincadeira democrática que incorpora quem passa pelo caminho, o Bumba-meu-boi já foi alvo de perseguições da polícia e das elites por ser uma festa mantida pela população negra da cidade, chegando a ser proibida entre 1861 e 1868.

Para a Análise do Discurso, todo enunciado carrega uma memória, estabelece relações com outros enunciados porque a linguagem é constitutivamente histórica. A historicidade está inscrita na linguagem e isso é percebido quando se recuperam processos discursivos que perpetuam e cristalizam a memória de uma época naquilo que é dito, por certos sujeitos, em certas condições de produção.

Nessa dimensão, o enunciado em análise traz à tona um momento em que, em São Luís, a festa sofria críticas ácidas e, assim, como muitas outras manifestações da cultura oriunda das camadas populares da sociedade, o Bumba-meu-boi era identificado como prática marginal. Percebe-se, então, uma vontade de verdade em apagar essa memória da festa, criando para ela uma identidade democrática, traço mais próximo ao que os discursos politicamente corretos desta época preconizam atualmente. Ao constituir a festa como lugar democrático, o enunciador se põe na ordem do discurso da diversidade, o qual prega a convivência harmônica entre as diferenças. Enunciando desse lugar, esse sujeito se inscreve, também, na ordem de um discurso constitucional, o qual, na Carta magna do Brasil, de 1988, no artigo 215, que inaugura a seção intitulada "Da cultura", estabelece que "O Estado garantirá a todos o pleno exercício dos direitos culturais e acesso às fontes de cultura nacional, e apoiará e incentivará a valorização e a difusão das manifestações culturais".

Ao prosseguir com a descrição da festa, novamente a diversidade é proposta como um traço característico do Bumba-meu-boi do Maranhão; a diversidade, desta vez, estará associada às múltiplas etnias constituintes da festa, conforme segue:

\footnotetext{
${ }^{2}$ Disponível em http://www.cidadeshistoricas.art.br/saoluis/sl_boi_p.php. Acesso em 10 de outubro de 2013.
} 
Para o maranhense, o bumba-meu-boi representa a tríplice miscigenação de seu povo, pelo entrelaçamento das culturas branca, negra e indígena, verificada nos personagens presentes no auto, no qual se destacam o dono da fazenda, Pai Francisco, Catirina, vaqueiros ou caboclos de fitas, caboclo real ou de pena, índios, doutor ou pajé, padre, Dona Maria (esposa do amo), os cazumbás (mascarados, espécie de palhaços) e o miolo, responsável por guiar o boi. As variações dos personagens ocorrem também por causa dos diferentes ritmos existentes no Maranhão. O que distingue esses sotaques, como são chamadas as músicas tocadas nos bois maranhenses, são os instrumentos musicais em destaque e a cadência do ritmo dada a cada tipo [...].

Esse texto conduz o leitor a estabelecer sentidos da festa popular à ideia de diversidade e das diferenças no que diz respeito à miscigenação. Assim, ao destacar a representação que a festa tem para o maranhense, o enunciador ocupa o lugar de quem prega a coesão social, por meio da convivência pacífica de opiniões divergentes, do respeito e valorização da diversidade, outrora não aceita. Com essa compreensão da heterogeneidade que caracteriza as sociedades contemporâneas, uma das marcas da condição pós-moderna, assegura Lyotard (2000), na qual impera a impossibilidade de qualquer compreensão de totalidade, esses enunciados inscrevem a festa do Bumbameu-boi nos meios midiáticos. Nesse enunciado, também, vai sendo desenhada concomitantemente uma imagem de cidade, para São Luís, como espaço da diversidade, lugar em que várias identidades se entrelaçam, confraternizam-se. Essa confraternização, no entanto, é possível a partir da cultura popular, proposta como signo de democracia de São Luís.

A seguir, analisa-se outro texto, alocado num sítio de Turismo ${ }^{3}$ proposto pelo governo do Estado do Maranhão da época. Nesse site, a festa é apresentada como espetáculo que se materializa em uma "explosão" de "cores" e "ritmos":

Verdadeira explosão de ritmos e cores, o Bumba-meu-boi é a mais importante manifestação folclórica do Maranhão. Suas raízes são negras, indígenas e européias, e suas origens se perdem no tempo. A brincadeira gira em torno de um auto, história encenada com muito humor pelos componentes, contando a história de Pai Francisco e Catirina. Ela, grávida, deseja comer a língua do boi Mimoso, o mais querido do patrão. Ele, para satisfazê-la, acaba cedendo, e mata o novilho. O crime é descoberto, Pai Francisco é preso e, em seguida, perdoado, quando o boi ressuscita, graças ao socorro de feiticeiros (grifos nossos).

Nesse espaço, o sujeito enuncia de um lugar oficial - o site de Turismo do Governo do Estado. Observa-se, aqui, também, o destaque à diversidade cultural materializada no caráter plural das etnias que constituem hoje uma das identidades maranhenses. Nesse sentido, convém observar o que afirma Hall (2006), ao relatar que ao lado da tendência em direção à homogeneização global, existe paralelamente uma

\footnotetext{
${ }^{3}$ Disponível em http://www.turismo.ma.gov.br/pt/. Acesso em 23 de fevereiro de 2013.
} 
fascinação pela diferença e pela mercantilização da etnia e da alteridade. Culturas até então deixadas à margem do processo de identidade nacional (no Brasil ressaltam-se negros e índios) passam a grandes atrativos da constituição de identidades. Desse modo, a miscigenação do maranhense aparece constantemente nesses textos como uma mercadoria que pode atrair consumidores interessados em encontrar diferenças. Também nota-se a instauração do aspecto da tradição da festa quando o enunciador marca: "suas origens se perdem no tempo", atribuindo, desse modo, valor ao produto.

O site segue expondo as características de cada sotaque, isto é, cada tipo de grupo de Bumba-meu-boi, que geralmente, tem adeptos ou simpatizantes de perfis bem diferentes:

Sotaque da Ilha - ocorre em toda a ilha de São Luís. Predominam as matracas e pandeirões. Boi da Maioba, Maracanã e Ribamar são alguns dos mais fortes representantes. São os chamados "batalhões pesados".

Sotaque de Pindaré - ocorre na região do vale do Pindaré, nos municípios de Viana, São João Batista e Pindaré. Também usa pandeiros (menores que os utilizados pelos bois da ilha) e matracas. Seu ritmo é mais lento.

Sotaque de Zabumba - O nome decorre das zabumbas (tambores), que são utilizados na brincadeira. Para alguns pesquisadores é o mais original de todos os bois. Se destacam nesse grupo o Boi de Lauro, Boi de Leonardo e de Antero.

Boi de Orquestra - Usa instrumentos de sopro como saxofones, clarinetas, flautas e banjos. Valorizam as coreografias. Os bois de Axixá, Morros e Rosário são os que melhor representam este sotaque. ${ }^{4}$

Essa segmentação dos grupos é internamente conhecida, no Estado, mas não deixa de ser apresentada com uma divisão que pode atrair diferentes públicos. Assim, há nesse elenco dos sotaques uma espécie de menu, que o turista poderá escolher a seu critério, fato que dialoga com o sentido de diversidade que permeia as descrições da festa e da cidade nesses sites.

O próximo texto a ser avaliado é também produzido pelo site oficial do governo do Estado, acessado em 2013. No trecho abaixo, observa-se a inserção da festa em uma rede de sentidos históricos, econômicos e globalizantes.

Trata-se da principal festa popular do Maranhão e seguramente uma das mais grandiosas do Brasil. Tem início dia 13 de junho, dia de Santo Antônio. Segue-se o dia de São João (24), São Pedro (29) e São Marçal (30 de junho). Nessa época a cidade fica repleta de arraiais e grande parte da população é envolvida nas comemorações. A maior atração deste período é o bumba-meu-boi, a mais importante manifestação folclórica do Estado, que distribui exuberância com seus ritmos, danças e cores (grifos nossos).

A festa é comparada a outras manifestações populares do país, logo no primeiro período, e colocada como festa de grande porte do Brasil, apontando para a identidade festeira que marca o povo brasileiro.

O período de festejo do Bumba-meu-boi, que em São Luís acontece do mês de maio - com os ensaios dos grupos - ao mês de julho, é uma espécie de diferencial

\footnotetext{
${ }^{4}$ Disponível em http://www.turismo.ma.gov.br/pt/. Acesso em 23 de fevereiro de 2013.
} 
utilizado pelo Turismo local para atrair visitantes, aspecto que converge para uma biopolítica (FOUCAULT, 1988), a qual determina tempos e espaços para a produção e gerenciamento dos sujeitos e sua produtividade.

A biopolítica é uma forma de produção de poder que, segundo Foucault, começa a se desenvolver no século XVIII. Por meio dela é possível gerenciar vida e morte, controlar a natalidade, a longevidade de uma sociedade. É principalmente por intermédio do controle do tempo e do espaço que os sujeitos têm seus corpos controlados e que um poder se organiza e organiza os indivíduos. Por esse princípio, a determinação do tempo para o trabalho e para o lazer, por exemplo, é uma forma de fazer os indivíduos produzirem riqueza. O tempo do lazer é cada vez mais importante em nossa sociedade, pois ele gera riqueza. As festas juninas, por isso, são cada vez mais pensadas pela indústria do turismo como uma forma importante de lucro, pois atrai lucro para a cidade. Ainda nesse fragmento, ressalta-se a presença dos "arraiais" como elemento que marca diferença dos festejos juninos maranhenses em relação a outros lugares. A palavra, talvez desconhecida por alguns turistas, significa o lugar onde as comemorações juninas acontecem na cidade e remete à memória rural que permeia os festejos da época. Nessa construção, no entanto, ela é citada como se o leitor conhecesse seu sentido, o que produz efeitos de sentidos ao texto.

Ainda nesse texto, ao comentar a identificação da população com o Bumba-meuboi, o enunciador afirma que "grande parte da população é envolvida nas comemorações", pontuando que há também aqueles que não se identificam com os festejos juninos, evitando, desse modo, o sentido de que todos os maranhenses simpatizam com essas manifestações.

\section{Considerações finais}

Este artigo buscou analisar imagens da cidade de São Luís constituídas a partir de dois sites voltados de alguma forma para temas turísticos, com base nos postulados da Análise de Discurso, de base foucaultiana.

A partir dos sites avaliados constata-se uma preocupação do enunciador em afirmar que a festa não é feita para os turistas, mas para a população. Se de um lado há enunciados construindo essa verdade, como o site 1, por outro lado, encontram-se afirmações que instituem a festa como espetáculo, determinando o lugar que a manifestação ocupa na rede discursiva da indústria cultural do Turismo, no Maranhão, como o site 2.

Na superfície e nas margens do dizer, os discursos sobre São Luís como cidade do Bumba-meu-boi se firmam no discurso da diversidade, discursos que edificam a cidade como espaço em que múltiplas identidades confluem, periferia e centro dialogam, cidade nova e antiga, índios, negros e europeus formam suas bases culturais. Para isso, os enunciadores retomam memórias, deslocam sentidos para construir figurações atuais de espaço para a capital maranhense.

Também observa-se que a emergência e o fortalecimento do Turismo, no Maranhão, bem como a consolidação da noção de patrimônio imaterial, acentuado na constituição de 1988, são acontecimentos que favoreceram o aparecimento do conceito de diversidade, o qual é mobilizado na divulgação da festa do Bumba-meu-boi e outras manifestações rítmicas, em São Luís. 
A exposição e a promoção de manifestações populares, por meio de qualquer canal de comunicação, como a internet, por exemplo, é um mecanismo de construção de uma identidade cultural local. Desse modo, nos sites avaliados é construída uma imagem de espaço democrático das diferenças não só para o Bumba-meu-boi, mas para a cidade de São Luís, apresentada como lugar em que várias identidades se celebram. Essa confraternização, no entanto, é possível a partir da cultura popular, proposta como signo de democracia da cidade de São Luís.

$\mathrm{Na}$ mídia eletrônica, os textos que falam sobre o Bumba-meu-boi colocam a festa como espaço democrático, lugar de diversidade porque são textos pensados para leitores de distintas identidades, de diferentes tribos, contribuindo para a construção de uma história do presente, uma nova memória para a capital, buscando fazer com que os sujeitos de diferentes localidades se identifiquem com manifestações construídas como tipicamente locais. Nesse sentido, vê-se que as várias imagens de uma cidade são frutos de jogos discursivos, históricos, investidos de poderes, que lhe determinam certas identidades.

\section{REFERÊNCIAS}

ABREU, Maurício. Sobre a memória das cidades. In: CARLOS, Ana Fani Alessandri et all (org.). A produção do espaço urbano: agentes e processo, escalas e desafios. São Paulo: Contexto, 2014.

BAUMAN, Zigmunt. Identidade. Entrevista a Benedetto Vecchi. Trad. bras. Carlos Alberto Medeiros. Rio de Janeiro: Jorge Zahar Editor, 2005.

CARVALHO, Conceição de Maria Belfort. A genealogia do patrimônio em São Luís: da Athenas à Capital da diversidade. Tese (Doutorado em Linguística e Língua Portuguesa). Faculdade de Ciências e Letras, Araraquara, 2009.

BRASIL. Constituição da República Federativa do Brasil, de 5 de outubro de 1988. Disponível em: <http://www.planalto.gov.br>. Acesso em: 25 out. 2011.

CRUZ, M. S. O discurso pela f(r)esta: espaço e produção de identidades. São Luís, Centrograf, 2008.

FERREIRA, Aurélio B. de Hollanda. Novo Dicionário da Língua Portuguesa. 2. ed. Rio de Janeiro: Nova Fronteira, 1986.

FOUCAULT, Michel. História da Sexualidade: a vontade de saber. Rio de Janeiro: Edições Graal, 1988.

A Arqueologia do Saber. Rio de Janeiro: Forense Universitária, 2009.

GREGOLIN, Maria do Rosário. Identidade: Objeto ainda não identificado? In: Estudos da Língua(gem). Vitória da Conquista: 2008.

HALBWACHS, M. A memória coletiva. Trad. de Beatriz Sidou. São Paulo: Centauro, 2006. 
HALL, Stuart. Identidade Cultural na pós-modernidade. Rio de janeiro: DP\&A, 2008.

GIDDENS, Anthony. Modernidade e identidade. Rio de Janeiro: Zahar Editor. 2002.

Foucault, Nietzsche e Marx. In: GIDDENS, A. Política, sociologia e teoria social. São Paulo: Ed. Unesp, 1998.

LEVI-STRAUS. Claude. Raça e História. In: Os Pensadores, vol. L, São Paulo, Abril Cultural: 1978.

LYOTARD, Jean-François. A condição pós-moderna. Rio de Janeiro: José Olympio, 2000.

ORLANDI, Eni P. (Org). Cidades atravessadas: os sentidos públicos no espaço urbano. Campinas, SP: Pontes, 2001.

Análise de discurso: princípios e procedimentos. 5. ed. São Paulo, Pontes, 2003.

PÊCHEUX, Michel. Discurso: estrutura ou acontecimento. Sâo Paulo: Pontes, 2002.

SANTOS, José Luís dos. O que é cultura? São Paulo: Brasiliense: 1994. (coleção Primeiros passos).

SOUZA, Marcelo Lopes de. A cidade, a palavra e o poder: práticas, imaginários e discursos heterônomos e autônomos na produção do espaço urbano. In: CARLOS, Ana Fani Alessandri et all (org.). A produção do espaço urbano: agentes e processo, escalas e desafios. São Paulo: Contexto, 2014. 